\title{
The Impact of the Moral Foundations Arguments on Early Adolescents
}

\author{
Kamila Stastna \\ (independent scholar; Pirna; Germany; kamila.stastna@seznam.cz) \\ ORCID: 0000-0003-0867-7393
}

\begin{abstract}
The empirical research reported in this article is based on the Moral Foundations Theory proposed by J. Haidt. Objectives. The author examines the impact of moral foundations arguments on early adolescents' moral judgments regarding violating moral rules and explores gender-related differences between moral foundations preferences. Method. The effect of moral foundations arguments was measured by a newly developed meta-ethical position test (MEPT). The MEPT consists of a pretest questionnaire, treatment by moral foundations arguments, and a posttest questionnaire. The sample contained 178 early adolescents from the Czech Republic (84 females and 94 males). The influence of the moral foundations arguments was analyzed by comparing the pretest with the posttest. Results. $91 \%$ of teenagers changed their moral judgment due to confrontations with the moral foundations arguments. A Wilcoxon signed-rank test found that the moral foundations arguments were significantly relevant, since the P-value was lower than 0.001 . The Mann-Whitney $U$ test revealed the importance of the gender aspect: P-value care equals 0.01 and liberty 0.01 . Girls have a preference for care foundation $(21 \%$ more than boys), while boys tended to liberty (27 \% more than girls). It seems that moral foundations arguments strongly change early adolescents' moral judgments and can be practically applied as a valuable platform for early adolescents' moral development.
\end{abstract}

Keywords: Moral Foundations Theory; moral judgment; moral competence; moral foundations argument; gender; moral development.

\section{Introduction}

Why do some arguments change our moral judgment and others not? What gives them the special power to convince us? Are some types of arguments universal? Certain studies claim that universal arguments do not exist, and according to them morality is relative (Prinz 2007; Sargissian 2014; Quintelier 2013); others suppose morality is objective and believe that universal arguments exist (Nichols 2004; Goodwin \& Darley 2012). This study is based on the Moral Foundations Theory (Haidt 2012) and aims to examine if arguments connected to moral foundations change early adolescents' moral 
decisions. In addition, the second aim is to investigate if gender makes a difference to moral foundations preference. Some studies do not reveal any significant differences between females and males (Krebs et al. 1994; Jaffee \& Hyde 2000), whereas others do (Benhabib 1985; Friesdorf 2015). This research uses a meta-ethical position test (MEPT) to measure the willingness to violate basic moral rules and the differences between the moral foundations preferences of males and females. A deeper understanding of moral foundations arguments can help teachers motivate their students and develop their morality naturally.

\section{Theoretical Background}

The Moral Foundations Theory was developed by the moral psychologist Jonathan Haidt and his colleagues, who investigated cultural differences regarding moral judgments and consequently found that a few moral values influence people worldwide. In conclusion, they suppose these values are innate; they develop gradually as a reaction to the human being's environment and are characterized as instinctive emotional dispositions. These fundamental values are labeled as moral foundations and comprise care/harm, liberty/ oppression, fairness/unfairness, loyalty/betrayal, authority/subversion, and purity/ disgust. However, moral foundations are, according to Haidt, universal; people just have different sensitivities towards them. Liberal-oriented people are more sensitive to care, liberty, fairness, and conservatives consider all categories equally (Haidt 2012). The preferences of moral foundations were measured by a self-report instrument, namely the Moral Foundation Questionnaire (MFQ), which has been examined worldwide. For example, a study involving 1,645 participants confirmed the validity of the MFQ in France (Métayer \& Pahlavan 2014). Likewise, a study conducted in New Zealand also affirmed its applicability. This research comprised 3.994 people and focused on the factor structure of the MFQ, which used confirmatory factors to perform an independent test of the MFQ (Davies, Sibley, \& Liu 2014).

Furthermore, the Moral Foundations Theory has been examined by neuroscience. Lewis and his colleagues scanned the brains of 70 young, healthy adults. According to their findings, people who have a preference for care and fairness were associated positively with the left dorsomedial PFC volume and associated negatively with bilateral precuneus volume. People who tended towards authority, loyalty, and purity showed an association to the bilateral subcallosal gyrus and the left anterior insula volume (Lewis et al., 2012). The influence of moral foundations regarding children and adolescents was indirectly investigated by Nucci, Turiel, and Roded, who focused primarily on moral objectivism. Their experiment involved 167 children and adolescents between 8-16 (17) years old, and showed that participants considered unconflicted situations, i.e., hitting, stealing, and not helping, as objectively wrong, whereas conflicted situations were judged differently in terms of age. For example, the participants 10-14 (11) years old were more likely than 
others to follow and agree with the nonprosocial choice, i.e., not helping someone in need (Nucci et al. 2017). According to some researchers, understanding care, welfare, and fairness develop very early in comparison with the sense of justice. The latter develops later and associates with reasoning about mathematical and physical problems (Damon 1975; Smetana et al. 2014).

The first pioneer who explored the gender aspect in the context of moral orientation preference is the well-known British moral psychologist Carol Gilligan (1982). She investigated the Kohlberg moral typology and found that women are attached to care; men to justice. Studies dealing with gender differences have predominated from that time. For example, Jaffee and Hyde (2000) conducted a meta-analysis from over one hundred studies; nevertheless, the results revealed only slight differences regarding care and justice. Accordingly, the study of Graham et al. (2011), which contained 34,476 adults and used MEQ, also found slight differences between the genders. Females scored higher in purity, care, and fairness, and males in authority and loyalty. In contrast, Niazi et al. (2020) showed there is a significant difference regarding care associated with females. This research was focused on a Pakistani sample comprising 300 male and female participants, and the MEQ was applied. Similarly, the results of the recent study conducted by Atari et al. (2020) involving a large sample of 336,691 adults from 67 countries revealed that females scored consistently higher on fairness, purity, and care.

\section{Hypotheses and Methodology}

The studies mentioned above confirm that moral foundations influence moral judgment. This study presumes that the arguments embedded into the moral foundations questionnaire can motivate or even manipulate the decision-making process.

Hence, the first hypothesis posits that the moral foundations arguments impact the willingness to change early adolescents' moral judgment.

The second hypothesis deals with gender differences regarding moral foundations preferences. The recent studies cited above presented controversial results. Some researchers highlight the significance of care regarding females, while others reveal different moral foundations preferences. For this purpose, this hypothesis cannot specify any moral foundations preference and thus broadly posits that gender influences early adolescents' moral foundations preferences.

The impact of moral foundations arguments and moral foundations preferences were measured by a meta-ethical position test. The MEPT is divided into three parts: the pretest questionnaire, treatment, and the posttest questionnaire. The pretest questionnaire comprises the six different short moral stories dealing with the violation of basic moral rules (i.e., John intentionally beats up his classmate). Participants rate the extent to which they consider this behavior correct on the Likert scale between $0-4$ $(0=$ strongly disagree and $4=$ strongly agree). The second part of the MEPT presents 
two sections. In the first section, respondents are asked to write motives for violating moral rules (i.e., Why might John intentionally beat up his classmate?). The second section presents the treatment by the moral foundation arguments aiming to justify violations of the moral rules (i.e., John intentionally beat up his classmate because his classmate had been intentionally spitting at him all day).

In the last part of the MEPT, the participants complete the posttest, which is the same questionnaire as the pretest. The MEPT is theoretically based on Moral Foundation Theory, and the construction of the six moral stories was influenced by the Konstanz Method of Dilemma Discussion (KMDD). These stories trigger thinking and emotion, the story's main protagonist usually has a name, and violates some standard moral rules, while the story vividly presents the daily life of adolescents (Lind 2019).

\section{Sample and Procedure}

Data were collected from six regular schools (in three different parts of the Czech Republic: north, south, and central regions) with the principals' cooperation. The sample comprised 178 early adolescents, 84 females and 94 males, aged 12 to 13. Pupils took the MEPT during class time in 2019, and the procedure took approximately 10 minutes.

\section{Assessment}

The relevance of moral foundations arguments was examined by a statistical comparison of pretest and posttest, applying a Wilcoxon signed-rank test, which compares two dependent samples of ordinal data (i.e., Likert scale). The importance of the gender aspect was investigated by a Mann-Whitney U test, which compares two independent samples (i.e., females and males).

\section{Results}

1) According to the results, $91 \%$ of early adolescents changed their moral judgments due to moral foundations arguments. The Wilcoxon signed-rank test revealed statistical differences between before and after treatment with all moral foundations arguments (see Table 1 and Figure 1$)^{1}$.

\begin{tabular}{|l|l|l|l|l|}
\hline $\begin{array}{l}\text { Moral } \\
\text { foundation } \\
\text { argument }\end{array}$ & Z-value & W-value & P-value & Result \\
\hline Betrayal & 8.4 & 1008 & $<0.00001$ & Significant impact \\
\hline Subversion & 7.3593 & 1397 & $<0.00001$ & Significant impact \\
\hline Harm & 8.4089 & 865.5 & $<0.00001$ & Significant impact \\
\hline Unfairness & 6.6287 & 1278 & $<0.00001$ & Significant impact \\
\hline Oppression & 7.7361 & 458.5 & $<0.00001$ & Significant impact \\
\hline
\end{tabular}

Table 1: Results of the Wilcoxon Signed-Rank Test.

1 The participants were also willing to violate moral rules in the pretest under the condition that they wrote an argument connected to moral foundations (i.e., John's case: self-defense, humiliation, self-defense, or revenge). 


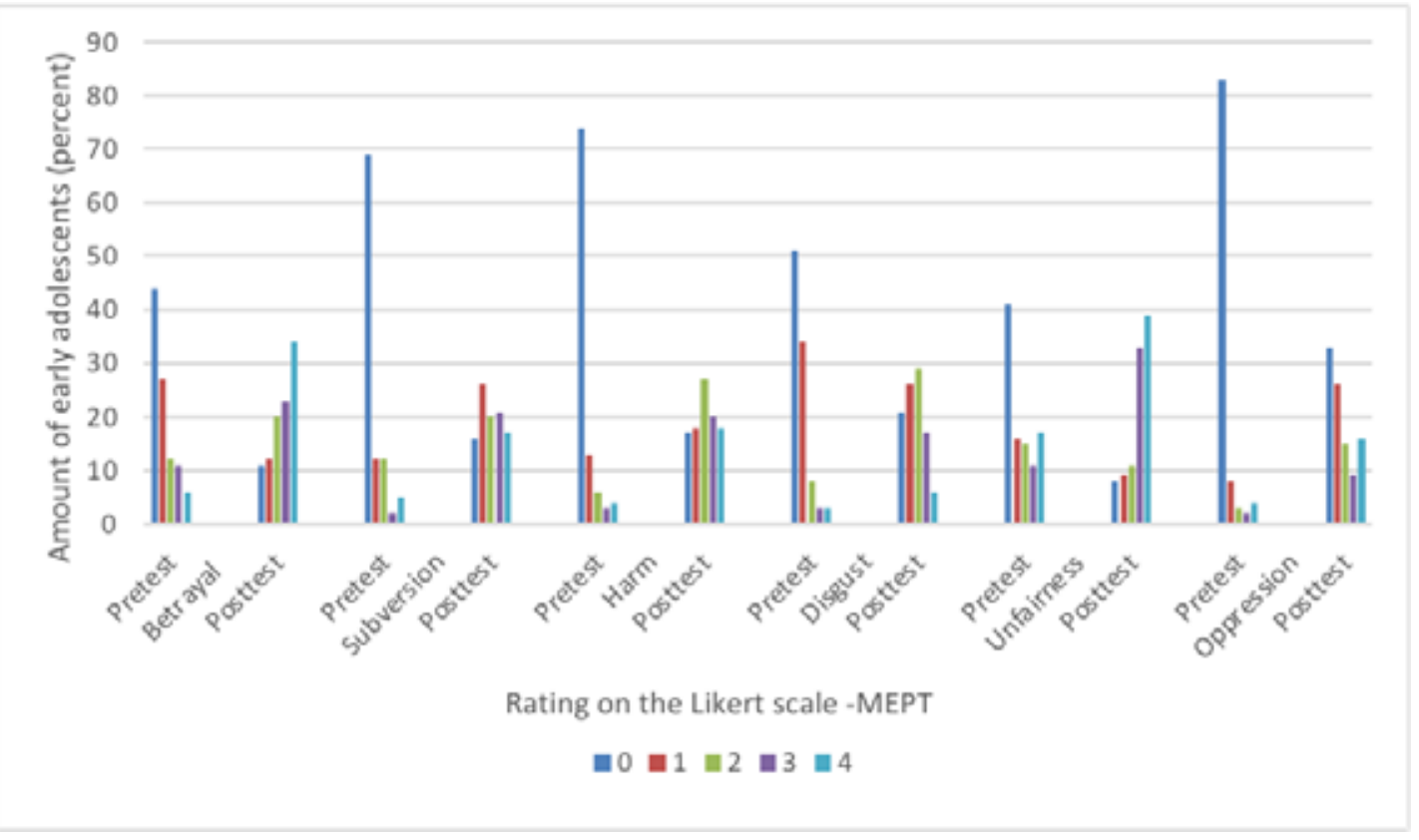

Figure 1: The impact of moral foundations arguments on moral judgment.

The Mann-Whitney U test revealed differences between females and males. A significant contrast was evident in oppression and harm, whereas others showed slight differences (see Table 2 and Figure 2).

\begin{tabular}{|l|l|l|l|l|}
\hline Moral foundation & Z-score & U-value & P-value & Results \\
\hline Unfairness & 1.71938 & 3283 & 0.08544 & not significant \\
\hline Oppression & 2.544 & 3039.5 & 0.01108 & significant \\
\hline Betrayal & 1.45854 & 3409 & 0.1443 & not significant \\
\hline Harm & 2.51609 & 3049 & 0.01174 & significant \\
\hline Subversion & 0.79425 & 3591 & 0.42952 & not significant \\
\hline Disgust & 0.80867 & 3464.5 & 0.41794 & not significant \\
\hline
\end{tabular}

Table 2: Results of the Mann-Whitney U Test.

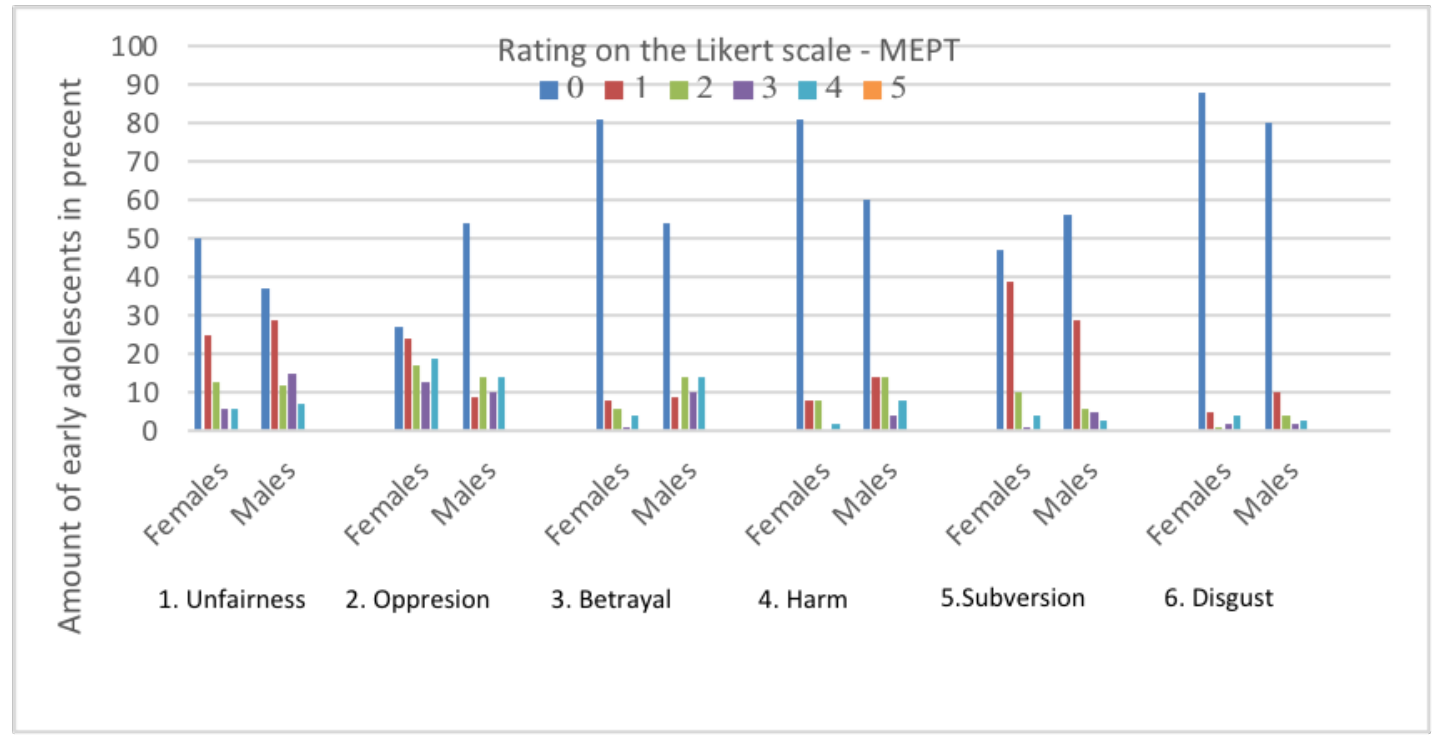

Figure 2: The gender impact on preferred moral foundations. 


\section{Discussion}

The results reveal the moral foundations arguments strongly influenced the willingness to change early adolescents' moral judgments, P-value $<0,001$ and support the finding of Haidt et al. (2012) and other studies (Yalçındağ et al. 2017; Davies, Sibley, \& Liu 2014; Métayer \& Pahlavan 2014; Zhang \& Li 2015; Lewis et al. 2012) dealing with the universality of moral foundations. On the other hand, the findings of this research do not follow the studies reporting that people tend to moral objectivism. For example, Goodwin and Darley (2012) found that people consider some moral acts as universal truths. Similarly, the research conducted by Nucci et al. (2017) showed that participants across ages considered negative unconflicted situations, i.e., hitting, stealing, and not helping, objectively wrong. However, moral foundations arguments were regarded universally in the sense of motivation (activating the emotions and cognitive processes of moral judgments); understanding what is right and wrong was not universal, but rather relative to other aspects.

It appears that early adolescents have in their mind some scenario, some motives, some a priori reasons why an agent can act, and possibly this is based on individual experiences (i.e., boys found more motives than girls why John could intentionally beat up his classmate). These findings differ from Goodwin and Darley (2012) and Nucci et al. (2017), probably due to the controversial terminology of moral objectivism and applied methodology. In contrast to Goodwin and Darley (2012), this study was not conducted with adults. Modern neuroscience emphasizes some brain differences regarding adults' and adolescents' brains (Blakemore 2013).

The second findings refer to the gender aspect in connection to moral foundations preferences. The Mann-Whitney U test found statistical importance related to liberty and care. Fifty-four percent of boys, compared to $27 \%$ of girls, were convinced that oppressing was wrong. Eighty-one percent of girls were convinced that hitting classmates was wrong, contrary to $60 \%$ of boys. These results follow Carol Gilligan's theory and similar studies, showing that females are more likely to have a preference for care than males (Gilligan 1983; Friesdorf 2015). Gender differences in the context of moral foundations preferences are controversial in the research, and the reason for this should be further investigated (Graham et al. 2011; Jaffee \& Hyde 2000; Atari et al. 2020; Niazi et al. 2020). This study has some limitations (i.e., conducted only in the Czech Republic, using nonparametric methods), and for this reason the findings cannot be generalized, and further studies are required.

Subsequent research could be conducted in different countries and religions; other studies could employ qualitative methods and apply neuroscience. Some studies could focus on practical innovation of moral education and investigate the impact of moral foundations arguments on mental perspective experiences. It could lead to the idea expressed by Gary Klein (2013). “I think helping people to arrive at insights isn't a 
question of pushing the insights on the people or trying to explain it in words, as much as it is helping people to gain the experience so they can see the inconsistency for themselves, and then all of a sudden the mental model will shift naturally and easily," Klein (2013, 214) suggests.

\section{Conclusion}

This study dealt with moral foundations arguments and moral judgment regarding early adolescents. The findings reveal that the moral foundations arguments powerfully influenced the moral decision process and that gender impacted moral foundations preferences. Girls were attached significantly to care; boys to liberty. However, the moral foundations arguments appear to be universal regarding motivation (activating emotional and rational processes of moral judgments), the sense of understanding what is right and wrong seems to be relative to many other aspects (i.e., personal experiences). Consequently, applying the moral foundations arguments in a class can motivate students to see, think, and discuss moral issues more profoundly. Additionally, adolescents can learn to be more open and not condemn what they do not truly understand.

\section{References}

Atari M., Lai M., \& Dehghani M. 2020. “Sex Differences in Moral Judgements Across 67 Countries," Proceedings of the Royal Society B: Biological Sciences 287(1937). DOI: 10.1098/rspb.2020.1201

Blakemore S. J. 2013. "The Adolescent Brain," in J. Brockman (Ed.), Thinking: The New Science of Decision-making, Problem-solving, and Prediction (pp. 115-131). New York: HarperCollins.

Benhabib S. 1985. "The Generalized and the Concrete Other: The Kohlberg-Gilligan Controverse and Feminist Theory," PRAXIS International 5(4):402-424.

Damon W. 1975. "Early Conceptions of Positive Justice as Related to the Development of Logical Operations," Child Development 46(2):301-312. DOI: 10.2307/1128122

Davies C. L., Sibley C. G., \& Liu J. H. 2014. "Confirmatory Factor Analysis of the Moral Foundations Questionnaire," Social Psychology 45(6):431-436. DOI: 10.1027/1864-9335/a000201.

Friesdorf R., Conway P., \& Gawronski B. 2015. “Gender Differences in Responses to Moral Dilemmas," Personality and Social Psychology Bulletin 41(5):696-713. DOI: $10.1177 / 0146167215575731$. 
Gilligan C. 1982. In a Different Voice: Psychological Theory and Women's Development. Cambridge, Mass. - London: Harvard University Press.

Goodwin G. P. \& Darley J. M. 2012. "Why Are Some Moral Beliefs Perceived To Be More Objective Than Others?," Journal of Experimental Social Psychology 48(1):250-256. DOI: 10.1016/j.jesp.2011.08.006

Graham J., Haidt J., \& Nosek B. A. 2009. "Liberals and Conservatives Rely on Different Sets of Moral Foundations," Journal of Personality and Social Psychology 96(5):1029-1046. DOI: 10.1037/a0015141

Haidt J. 2012. The Righteous Mind: Why Good People Are Divided by Politics and Religion. New York: Pantheon Books.

Jaffee S. \& Hyde J. S. 2000. "Gender Differences in Moral Orientation: A Meta-analysis," Psychological Bulletin 126(5):703-726. DOI: 10.1037/0033-2909.126.5.703.

Klein G. 2013. Seeing What Others Don't. New York: Public Book Affairs.

Krebs D. L., Vermeulen S. C., Denton K. L., \& Carpendale J. I. 1994. „Gender and Perspective Differences in Moral Judgement and Moral Orientation," Journal of Moral Education 23(1):17-26. DOI: 10.1080/0305724940230102

Lewis G. J., Kanai R., Bates T. C., \& Rees G. 2012. "Moral Values Are Associated with Individual Differences in Regional Brain Volume," Journal of Cognitive Neuroscience 24(8):1657-1663. DOI: 10.1162/jocn_a_00239

Lind G. 2019. How To Teach Moral Competence. New: Discussion Theater. Berlin: Logos Verlag.

Métayer S. \& Pahlavan F. 2014. "Validation de l'adaptation Française du Questionnaire des Principes Moraux Fondateurs" [Validation of the Moral Foundations Questionnaire in French], Revue Internationale de Psychologie Sociale 27(2):79107.

Niazi F., Inam A., \& Akhtar Z. 2020. „Accuracy of Consensual Stereotypes in Moral Foundations: A Gender Analysis," PLOS ONE 15(3). DOI: 10.1371/journal. pone.0229926.

Nichols S. 2004. "After Objectivity: An Empirical Study of Moral Judgment," Philosophical Psychology 17(1):3-26. DOI: 10.1080/0951508042000202354.

Nucci L., Turiel E., \& Roded A. D. 2017. "Continuities and Discontinuities in the Development of Moral Judgments," Human Development 60(6):279-341. DOI: $10.1159 / 000484067$.

Prinz J. 2007. The Emotional Construction of Morals. Oxford: Oxford University Press.

Quintelier K., Fessler D., Smet D. 2013. "The Moral Universalism-Relativism Debate," Klesis Revue Philosophique 27:211-262.

Sarkissian H., Park J., Tien D., Wright J. C., \& Knobe J. 2011. “Folk Moral Relativism,” Mind \& Language 26(4):482-505. DOI: 10.1111/j.1468-0017.2011.01428.x. 
Smetana J. G., Jambon M., \& Ball C. 2014. “The Social Domain Approach to Children's Moral and Social Judgments," in M. Killen \& J. G. Smetana (Eds.), Handbook of Moral Development (pp. 23-45). Hove, East Sussex: Psychology Press.

Yalçındağ B., Özkan T., Cesur S., Yilmaz O., Tepe B., Piyale Z. E., et al. 2017. "An Investigation of Moral Foundations Theory in Turkey Using Different Measures," Current Psychology 38(2):440-457. DOI: 10.1007/s12144-017-9618-4.

Zhang Y. \& Li S. 2015. "Two Measures for Cross-Cultural Research on Morality: Comparison and Revision," Psychological Reports 117(1):144-166. DOI: 10.2466/08.07.pr0.117c15z5. 